\title{
Géneros y formatos para la televisión digital. Análisis en los países andinos*
}

\author{
Recibido: 2015-03-26 -Enviado a pares: 2015-04-10 -
}

Aprobado por pares: 2015-04-30 Aceptado: 2015-05-04

\author{
Abel Suing* \\ Verónica González*** \\ Ignacio Aguaded $\cdots$
}

\begin{abstract}
Resumen
El propósito de la investigación es analizar los formatos de televisión vigentes en la transición hacia la televisión digital terrestre en los países andinos e identificar alternativas para la televisión local. La investigación se justifica en razón del apagón analógico entre el 2018 y 2020. La metodología es cualitativa y cuantitativa; los instrumentos son análisis de contenidos y entrevistas semiestructuradas. Los resultados permiten concluir que los contenidos de producción nacional están vinculados con la actualidad. Los elementos que influyen en la creación de contenidos están relacionados con factores de identidad, recursos económicos, talento humano y narrativas. La hibridación de formatos que promuevan la cultura es una opción para las estaciones locales.

Palabras clave: Televisión digital, televisión local, formatos audiovisuales, identidad cultual, géneros televisivos.
\end{abstract}

* El propósito de la investigación es determinar los formatos televisivos vigentes en la transición hacia la TDT en los países andinos e identificar el formato adecuado para que los canales de televisión locales generen nuevos contenidos. El silogismo de la investigación es: La implementación de la TDT supone mejorar la calidad de la televisión (ECUADOR)

** Doctor en Comunicación (2012) por la Universidad de Santiago de Compostela. Docente del Departamento de Ciencias de la Comunicación de la Universidad Técnica Particular de Loja (UTPL), investiga sobre políticas de comunicación y televisión. Integrante de la Sociedad Ecuatoriana de Investigadores de la Comunicación. Exbecario SENESCYT. Dirigió entre 2004 y 2010 la Escuela de Comunicación Social de la UTPL. En 2011 dirigió el proyecto "Adaptación del Plan Modelo de estudios periodismo de UNESCO a la malla curricular de comunicación de UTPL". arsuing@utpl.edu.ec

*** Docente investigadora en las cátedras de Cine y Teoría de la Imagen en la Universidad Técnica Particular de Loja entre el 2008-2014. Doctoranda en la Universidad Santiago de Compostela. Tema de investigación Documentales de Género. DEA en la Universidad Santiago de Compostela "Comunicación y Periodismo" (2009). Licenciada en Comunicación Social. Realizadora audiovisual de Documentales y Ficción. vegonzalez@utpl.edu.ec

**** Catedrático de Universidad del Departamento de Educación de la Universidad de Huelva (España). Presidente del Grupo Comunicar, colectivo veterano en España en Educomunicación, y Editor de la Revista Científica Iberoamericana «Comunicar» (indexada en JCR, Scopus, ERIH, RECYT...). Es además Director del Grupo de Investigación «Ágora», responsable de múltiples investigaciones nacionales e internacionales y de la dirección de numerosas tesis doctorales. Es director del Máster Internacional Interuniversitario de Comunicación y Educación Audiovisual (UNIA/UHU) y subdirector del Programa Interuniversitario de Comunicación (US, UMA, UCA y UHU). Ha sido vicerrector de Tecnologías, Innovación y Calidad de la Universidad de Huelva durante 7 años (2005-12) aguaded@uhu.es 


\title{
Genres and formats for digital television. Analysis in the andean countries
}

\begin{abstract}
The purpose of the research is to analyze the current television formats in the transition to digital terrestrial television in the Andean countries, and to identify alternatives for the local television. The research is justified in view of the analog blackout that will occur between 2018 and 2020. The methodology is both qualitative and quantitative; the instruments are content analyses and semi-structured interviews. The results allow concluding that the local production contents are linked to current events. The elements that influence the creation of contents are related to factors of identity, economic resources, human talent and narratives. The hybridization of formats promoting culture is an option for the local stations.
\end{abstract}

Key words: Digital television, local television, audiovisual formats, cultural identity, television genres.

\section{Gêneros e formatos para televisão digital. Análise nos países andinos}

\begin{abstract}
Resumo
O objetivo da pesquisa é analisar formatos de televisão existentes na transição para a televisão digital terrestre nos países andinos e identificar alternativas para a televisão local. A pesquisa justifica-se pela transição para o digital entre 2018 e 2020. A metodologia é instrumentos qualitativos e quantitativos são de análise de conteúdo e entrevistas semi-estruturadas. Os resultados mostram que o conteúdo de produção interna estão ligadas com hoje. Os elementos que influenciam a criação de conteúdo estão relacionadas a fatores de identidade, os recursos financeiros, humanos e talento narrativo. Hibridização de formatos para promover a cultura é uma opção para as estações locais.

Palavras-chave: A televisão digital, a televisão local, formatos audiovisuais, identidade cultual, gêneros televisivos.
\end{abstract}




\section{Introducción}

La televisión digital terrestre (TDT) ingresa al escenario audiovisual comprometida con atender las demandas de calidad de la televisión analógica de señal abierta. La televisión digital "es un sistema de transmisión que consiste en el muestreo y codificación de imágenes y sonidos en un flujo de datos binarios (ceros y unos)" (Bizberge, Krakowiak, Labate $\&$ Morone, 2013, p. 176).

La emisión digital de audio y vídeo, y el incremento de número de canales son parte de los cambios de calidad que la TDT trae consigo, pero hay otros, de fondo, como "una oferta televisiva más amplia y plural" (Ros, 2009, p. 26) y la "reconfiguración en los modos de producción, distribución y consumo" de contenidos (Bizberge $\varepsilon$ al., 2013, p. 176).

El propósito de la investigación es determinar los formatos televisivos vigentes en la transición hacia la TDT en los países andinos e identificar el formato adecuado para que los canales de televisión locales generen nuevos contenidos. El silogismo de la investigación es: La implementación de la TDT supone mejorar la calidad de la televisión. La calidad de la televisión es la sumatoria de elementos de forma y fondo. Algunos elementos de forma son: audio, vídeo, emisión digital para dispositivos móviles e interactividad, entre otros. Los elementos de fondo son los contenidos. Por lo tanto, la implementación de la TDT supone mejorar los formatos de los programas de televisión.

La investigación se justifica en razón del apagón analógico que ocurrirá en los países andinos entre el 2018 y 2020 (tabla 1) e implica lógicas de trabajo multidisciplinario para elaborar contenidos que alimenten la nueva señal en formatos de gran aceptación y sostenibilidad para estaciones nacionales y locales.

Tabla 1. Fechas de apagón analógico

\begin{tabular}{|l|c|l|}
\hline \multicolumn{1}{|c|}{ Países } & Estándares de TDT & \multicolumn{1}{c|}{ Fechas } \\
\hline Colombia & DVB-T & 31 de marzo de 2019 \\
\hline Bolivia & ISDB-T & No definido aún \\
\hline Ecuador & ISDB-T & 31 de diciembre de 2018 \\
\hline Perú & ISDB-T & 28 de julio de 2020 \\
\hline
\end{tabular}

Fuente: Fayer Wayer 2014 y páginas Web oficiales

Las nociones de diálogo, relación y proximidad están en la génesis de la televisión, porque es lenguaje, conversación, compañía, una manera de contar historias y un modelo de distribuirlas (Román, 2012, p. 802; Mikel Ortiz en Scolari, 2103, p. 72; Rincón, 2013, p. 99). "Ver televisión es hablar, es comentar, es comer, es jugar y todo a la vez... se inserta en la vida cotidiana". (Martín-Barbero en Rincón, 2013, p. 102)

Conversar es, según la Real Academia Española, hablar, tratar, comunicar y tener amistad con otra u otras personas, lo que implica mantener diálogos que irán de lo superfluo a lo profundo rodeados de un carisma de recreación que hará cercana, fluida y 
resuelta la relación; por ello el entretenimiento identifica a la televisión, está implícito en su enunciación. La televisión es "un medio utilizado para el entretenimiento antes que para informarse o interesarse por los temas periodísticos". (Rincón, 2013, p. 101), pero también constituye "una ventana al mundo, al conocimiento y a la información de lo más diversa" (Marín, 2205, pp. 227).

El potencial incremento de contenidos en la TDT ayudaría a democratizar la creación audiovisual y la participación ciudadana (Hellín, Rojo \& San Nicolás, 2009, p. 176) pero también cuestiona la calidad de los programas: ¿Existirá equilibrio entre entretenimiento, información, opinión, ficción, cultura y otros géneros? La TDT es reto y oportunidad en tanto pase de ser un cambio tecnológico a un cambio de relación entre creadores y ciudadanos que cuenten con una vía para la interacción (De Moraes, 2007, p. 103).

Los cambios de fondo que aspira provocar la TDT parten de considerar que la televisión "en el tiempo no ha significado una mejora en la calidad de sus productos" (Marín, 2005, p. 226); además, "la calidad y el atractivo de los contenidos son quizá el aspecto que ha despertado más críticas en la transición digital" (Academia TV en López \& Gómez, 2012, p. 260); tal vez porque a los operadores les interesa más la rentabilidad que los contenidos de calidad, pesa el criterio económico que repite "modelos de éxito, lo que suele dejar un margen muy escaso para la innovación. En estas circunstancias prima el éxito a corto plazo, antes que la búsqueda de la calidad". (León, 2008, p. 20). Pero ¿qué es calidad en televisión? Probablemente ahí radiquen las claves que guíen el proceso de implementación de la televisión digital.

Estudios previos señalan que "el debate sobre la calidad en televisión es tan antiguo como el propio medio" (Camacho 2005, p. 30), "el concepto de calidad televisiva es muy complejo y no existe un consenso que permita codificar esta cualidad de manera unívoca" (Vázquez, 2009, p. 845); algunas definiciones están vinculadas al proceso técnico y otras a la satisfacción de las audiencias. Calidad en televisión es brindar a la comunidad información profunda e independiente que ayude a cumplir el derecho a la comunicación. También acerca contenidos que estimulan la cultura, la educación, el conocimiento y el entretenimiento (Aguaded, 2005, p. 18; Marín, 2005, p. 227; León, 2008, p. 17). Para el Consejo Audiovisual de Cataluña, calidad es el resultado de variedad programática, pluralismo, valores, innovación en géneros y formatos (Camacho, 2005, p. 30); por lo tanto, es necesario analizar los programas y formatos porque se conocerán las posibilidades de la TDT para provocar cambios en la calidad de la televisión.

El formato de televisión es "el conjunto de los elementos de los que se compone un programa, los elementos que permanecen invariables en cada una de sus emisiones" (Guerrero, 2010, p. 239); el modo de "diseñar el producto televisivo, las formas que toma el producir, entretener, empaquetar, programar y mercadear la televisión" (Rincón, 2013, p. 46). Los géneros televisivos son "un conjunto de programas que se organizan según un conjunto de criterios de orden temático y expresivo, cultural y comunicacional" (Hernández, 2008, p. 32). A su vez, el programa de televisión es "la unidad básica de la parrilla de programación de una cadena de televisión... [el] esquema jerárquico: género representa 
la categoría mayor, seguido por el formato, y por último, el programa, que implica la materialización audiovisual del proyecto" (Guerrero, 2010, p. 239).

Los formatos se adaptan a diferentes géneros y contextos, según el momento y las condiciones de producción, contienen la información necesaria para configurar los programas de televisión, así es posible volverlos a elaborar en "otro lugar y en otro momento... [el] contenido es adaptado a las peculiaridades de cada mercado televisivo" (Guerrero, 2010, p. 240). Esta plasticidad ha permitido consolidar formatos internacionales; según este modelo las estaciones compran "éxitos asegurados", evitan riesgos y disminuyen los costos de investigación. El afán de maximizar los formatos y evitar la complejidad de crear nuevas propuestas derivó en la combinación de géneros y la mezcla de contenidos ya testados (Guerrero, 2010, p. 264), lo que hoy es una de las principales características de "la televisión contemporánea: hibridación de géneros, sincretismo entre realidad y ficción, fragmentación e innovación" (Galán-Fajardo y Rueda-Laffond, 2011, p. 85).

La hibridación de géneros está en alternativas como el infoentretenimiento, "una mezcla de información y entretenimiento, de realidad y de espectáculo... [que] atrae la atención del telespectador apelando a lo más hondo de los sentimientos" (Galán-Fajardo E Rueda-Laffond, 2011, p. 90), cercano a un proceso de "ficcionalización" (Pajoni, De La Torre \& Besada, 2013, p. 159). Otro ejemplo es el documental televisivo cuyos autores "se han visto obligados a introducir elementos propios de la ficción para entretener al público" (Galán-Fajardo \& Rueda-Laffond, 2011, p. 91) o como las televisoras mexicanas que "han adaptado los géneros televisivos desarrollados en Estados Unidos de América principalmente y, desde el año 2000, optaron por la introducción del reality show" (SotoHernández E Naumis-Peña, 2014, p. 80).

La adaptación no siempre es adecuada, más aún cuando se busca atender a la audiencia con base en el respeto de sus derechos; esto explicaría que la televisión actual no "motiva porque no ofrece novedades con un auténtico factor diferencial con respecto a la oferta de siempre... le falta variedad y se abusa de la tv basura" (López, González \& Medina, 2011, p. 111). El punto de encuentro entre las expectativas de los televidentes y la oferta de contenidos parece estar en la proximidad, la realidad cercana e inmediata, partir de lo local para ir al mundo.

"Unidad lingüística, cercanía geográfica, similitud en valores culturales tradiciones e historia compartida son algunas de las categorías que explicarían la preeminencia de los productos locales, nacionales y regionales sobre las producciones internacionales en las parrillas de programación" (Danta, 2009, p. 579); es decir, los contenidos sobre comunidad que son factibles de elaborar en estaciones locales serían la vía para proponer formatos frente a la adaptación de esquemas. En relación con lo señalado, Jerónimo Rivera (2014) menciona que "aunque la penetración del cable (de forma legal e ilegal) es tan alta en el país, la inmensa mayoría de los colombianos siguen prefiriendo la televisión programada por los dos canales privados colombianos (que son realmente públicos, aunque de capital privado)", es decir, hay vocación por lo local y por lo cercano. 
La creación de contenidos, la exploración de formatos y la proximidad derivarían en proveer a la TDT una oferta diferente que haga atractiva su señal no solo por la calidad técnica sino por la programación. En un escenario donde el crecimiento de televisión de pago significa migración de audiencias, más del $55 \%$ de las personas en Latinoamérica cuentan con acceso a este servicio (LAMAC, 2013). La TDT tiene la oportunidad y el compromiso de constituir una opción de valor al alcance de los ciudadanos.

El proceso de implementación de TDT en Latinoamérica genera expectativas por conocer las experiencias nacionales de creación de contenidos y la forma como incorporarán las potencialidades de interactividad y los servicios avanzados (Román, 2012, p. 804).

Lo que ahora emite la televisión analógica está cargado de espectáculo en formatos lúdicos en su mayoría de origen extranjero que han pretendido insertarse en la idiosincrasia local; hay altas proporciones de ficción en los espacios de entretenimiento. Además, han existido intenciones, con poco éxito, de trasladar a la pantalla los formatos de radio; otro caso es la metamorfosis del infoentretenimiento que en ocasiones ha derivado en crónica roja o "farandulización", y en lugar de abonar con datos y contextualización provoca desinformación.

Los análisis académicos han sugerido que la televisión debe escuchar más a los ciudadanos, provocar su participación, porque es una vía para explorar formatos en los que haya apertura a nuevos temas, enfoques y producciones independientes; debería valorarse la vida cotidiana, la composición cultural, étnica y geográfica de cada país para depender menos de la producción foránea. El ideal es "una televisión diversa, crítica, democrática, no sumisa al poder" (Rincón, 2013, p. 185).

La televisión de calidad cuesta. Incorporar más voces, más imágenes, más país en la pantalla significa invertir dinero, así la exploración de calidad está enfrentada a la limitación de recursos y la creciente oferta de la televisión de pago. Ante ello las audiencias jóvenes, nativos digitales, ya familiarizados con mejores definiciones en audio y vídeo, no encuentran en la programación local y regional opciones interesantes; entonces ¿qué formato debe elaborarse en la televisión local?

Cubrir la diversidad de formas exige "imaginar formatos que hacen televisión como nosotros, en nuestro estilo, tomando la forma de nuestra forma cultura: televisión made in Latinoamérica: televisión que innova desde la identidad" (Rincón, 2013, p. 48); esto supone evaluar las adaptaciones frente a elementos cercanos como bailes, danzas, calles, plazas, tertulias, debates y cultura local.

Las razones del distanciamiento entre contenidos y realidad inmediata estarían en la cultura y el mercado. La cultura como expresión de identidad y manifestaciones vitales no está en la televisión tal vez porque no es rentable, por falta de creatividad, exceso de burocratismo o por prejuicios. Si el entretenimiento es la clave para llegar a los televidentes, entonces el desafío es "entusiasmar a una audiencia acostumbrada a la narrativa fácil" (Amado, 2013, p. 116); crear una relación "diferente con audiencias a partir de nuevos 
esquemas narrativos y tecnológicos que promuevan el uso y la interacción con los públicos consumidores" (Piñón, 2013, pp. 78), precisamente ahora que la TDT incrementa el número de frecuencias, o sea más horas de emisión que requieren contenidos.

Sobre la base de lo expuesto la investigación tiene por objetivos:

- Conocer los géneros y los formatos emitidos en las estaciones nacionales de televisión, líderes en audiencia, de los países andinos.

- Determinar los factores que influyen en la creación de formatos y contenidos de televisión local.

- Establecer los formatos que realizadores, investigadores y ejecutivos audiovisuales estiman pertinente elaborar en estaciones locales de televisión de los países andinos.

Las hipótesis de trabajo son:

- Los formatos más emitidos en las estaciones de televisión de los países andinos corresponden al género de entretenimiento y son producciones extranjeras.

- Las limitaciones para generar formatos están relacionadas con la creatividad más que con otros factores.

- Los formatos sugeridos a las estaciones locales de televisión para la transición hacia la TDT son adaptaciones con alto componente local.

\section{Metodología}

La investigación emplea métodos cualitativos y cuantitativos. Los instrumentos utilizados son análisis de contenidos y entrevistas semiestructuradas. La información utilizada para el análisis de contenidos fue publicada, entre el 05 y 18 de mayo de 2014, en los sitios Web de las estaciones de televisión líderes, públicas y privadas, que emiten en señal abierta en los países Andinos: Bolivia, Colombia, Ecuador y Perú (CAN, 2014).

Las clasificaciones del estudio "Preferencia juvenil en nuevos formatos de televisión. Tendencias de consumo en jóvenes de 14 a 25 años" del Observatorio del Ocio y Entretenimiento Digital (OCENDI, 2012) y de los informes del Observatorio Iberoamericano de Ficción Televisiva OBITEL (Orosco \& Vassallo, 2013) sirvieron de referencias para los géneros y formatos de televisión analizados en la presente investigación.

La selección de estaciones se realizó con base en las cuotas de pantalla presentadas en el informe OBITEL 2013 (tabla 2), con la particularidad de que en Bolivia no hay medición de audiencias (TDT-Foro Latinoamérica, 2013); por ello fueron utilizadas las cifras de publicidad en canales de televisión (Bolivia informa, 2012) y la referencia al canal público de Bolivia señalada en el estudio "Situación de la televisión pública en América Latina" (Fuenzalida, 2011, p. 2) 
Tabla 2. Muestra de estaciones de televisión

\begin{tabular}{|l|l|l|l|}
\hline \multicolumn{1}{|c|}{ País } & \multicolumn{1}{|c|}{ Nombre de la estación } & \multicolumn{1}{c|}{ Propiedad } & \multicolumn{1}{c|}{ Share } \\
\hline \multirow{3}{*}{ Bolivia } & ATB & Privada & $21,8 \%$ \\
\cline { 2 - 4 } & Bolivia TV & Pública & $\mathrm{n} / \mathrm{d}$ \\
\hline \multirow{3}{*}{ Colombia } & Caracol & Privada & $51,7 \%$ \\
\cline { 2 - 4 } & Señal Colombia & Pública & $0,4 \%$ \\
\hline \multirow{3}{*}{ Ecuador } & Ecuavisa & Privada & $15,5 \%$ \\
\cline { 2 - 5 } & Ecuador TV & Pública & $\mathrm{n} / \mathrm{d}$ \\
\hline \multirow{3}{*}{ Perú } & América Televisión & Privada & $22,1 \%$ \\
\cline { 2 - 5 } & TV Perú & Pública & $0,4 \%$ \\
\hline
\end{tabular}

Fuente: Orozco y Vassallo OBITEL, 2013.

Las entrevistas semiestructuradas corresponden a 10 expertos vinculados a la televisión del área andina; son realizadores, investigadores y ejecutivos audiovisuales; entre los profesionales hay dos que pertenecen al área cinematográfica consultados en razón de las características de producción y por la adaptación de obras fílmicas hacia la televisión.

\section{Análisis y resultados}

Al final del período de observación se lograron tabular 352 programas de televisión que equivalen a 1115 horas de contenidos emitidos en estaciones públicas y privadas del área andina; estos contenidos son de generación nacional y extranjero, según está detallado en la siguiente tabla.

Tabla 3. Horas de contenidos de televisión

\begin{tabular}{|l|c|c|c|}
\hline \multirow{2}{*}{ Origen } & \multicolumn{2}{c|}{ Propiedad } & \multirow{2}{*}{ Totales } \\
\cline { 2 - 3 } & Privada & Pública & \\
\hline Nacional & 375,5 & 339,75 & 715,25 \\
\hline Extranjero & 260,25 & 139,5 & 399,75 \\
\hline Total & 635,75 & 479,25 & 1115 \\
\hline
\end{tabular}

Elaboración propia

El 64 \% de los contenidos emitidos en la televisión del área andina es de origen nacional; $36 \%$, de origen extranjero. Según la propiedad del emisor, 57 \% han sido emitidos en estaciones privadas, y 43 \%, en públicas. En relación con las variables propiedad del emisor y origen de los contenidos, la mayor cuota corresponde a contenidos de origen nacional en estaciones privadas, y la menor, a contenidos de origen extranjero en estaciones públicas. 
Los datos ilustran el empeño de operadores públicos y privados en una crear una televisión con identidad regional. Hay una apuesta por contenidos nacionales frente a extranjeros, en gran medida, cubiertos por la iniciativa privada que, además, es la que mantiene altos niveles de rating y share.

Gráfico 1. Géneros de televisión emitidos

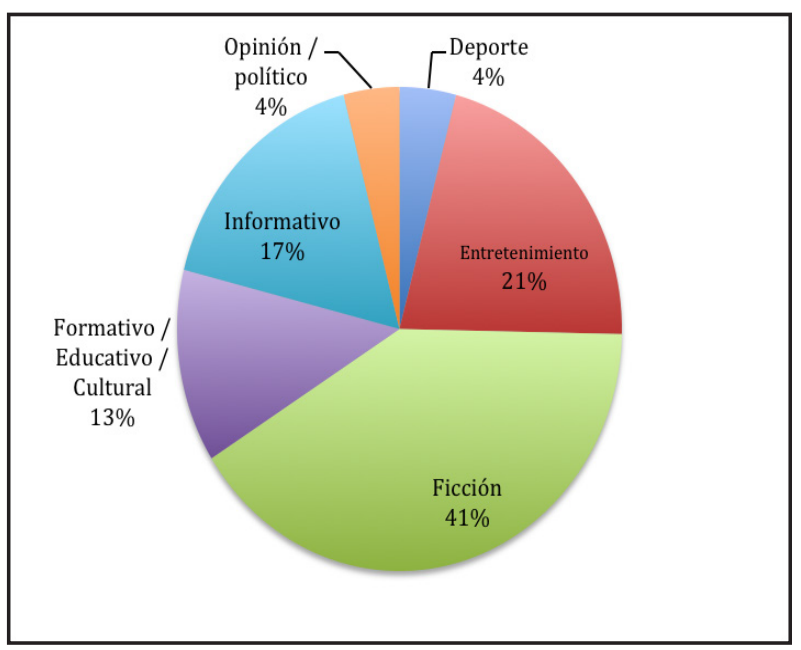

Los géneros presentes en la televisión andina, en relación con las horas de contenidos emitidos, son: ficción (41 \%); entretenimiento (21 \%); informativo (17\%); formativo, educativo y cultural (13\%); opinión, político y deporte con cuotas similares (4\%).

Ficción y entretenimiento suman el 62 \% de horas emitidas. Poco más de un tercio de los contenidos de la televisión del área andina corresponde a formatos educativos, de información, opinión y deporte. Hay una clara necesidad de equilibrar la emisión de contenidos en todos los géneros de televisión.

Tabla 4. Contenidos de televisión por formato, origen y propiedad del emisor

\begin{tabular}{|c|c|c|c|c|c|}
\hline \multirow{3}{*}{$\begin{array}{c}\text { Nombres de } \\
\text { formatos }\end{array}$} & \multicolumn{4}{|c|}{ Horas de emisión de formatos } & \multirow{3}{*}{ Totales } \\
\hline & \multicolumn{2}{|c|}{ Producción de origen nacional } & \multicolumn{2}{|c|}{ Producción de origen extranjero } & \\
\hline & $\begin{array}{c}\text { Emisión en medios } \\
\text { privados }\end{array}$ & $\begin{array}{c}\text { Emisión en medios } \\
\text { públicos }\end{array}$ & $\begin{array}{c}\text { Emisión en medios } \\
\text { privados }\end{array}$ & $\begin{array}{c}\text { Emisión en medios } \\
\text { públicos }\end{array}$ & \\
\hline Caricatura & 0 & 24,75 & 28,5 & 56,25 & 109,5 \\
\hline Cine & 26 & 23 & 43,5 & 31,25 & 123,75 \\
\hline Comedia & 13,75 & 0 & 9,5 & 1 & 24,25 \\
\hline Concurso & 6 & 0 & 7,25 & 0 & 13,25 \\
\hline Documental & 4,25 & 40,25 & 1 & 6,5 & 52 \\
\hline Educativo & 10,25 & 15 & 1,5 & 4,5 & 31,25 \\
\hline
\end{tabular}




\begin{tabular}{|l|c|c|c|c|c|}
\hline \multirow{2}{*}{$\begin{array}{c}\text { Nombres de } \\
\text { formatos }\end{array}$} & \multicolumn{4}{|c|}{ Horas de emisión de formatos } & \multirow{2}{*}{ Totales } \\
\cline { 2 - 5 } & $\begin{array}{c}\text { Emisión en medios } \\
\text { privados }\end{array}$ & $\begin{array}{c}\text { Emisión en medios } \\
\text { públicos }\end{array}$ & $\begin{array}{c}\text { Emisión en medios } \\
\text { privados }\end{array}$ & $\begin{array}{c}\text { Emisión en medios } \\
\text { públicos }\end{array}$ & \\
\hline Farándula & 1,5 & 4,75 & 0 & 0 & 6,25 \\
\hline Fútbol & 11 & 10 & 1,75 & 0 & 22,75 \\
\hline $\begin{array}{l}\text { Info entrete- } \\
\text { nimiento }\end{array}$ & 9 & 30 & 3,25 & 2,5 & 44,75 \\
\hline Magacín & 107,25 & 102,1 & 2,5 & 2,5 & 214,35 \\
\hline Noticias & 134,5 & 71,65 & 0,5 & 6 & 212,65 \\
\hline Reality shows & 23,75 & 6,5 & 7,5 & 2 & 39,75 \\
\hline Serie & 7 & 11,75 & 64 & 15,25 & 98 \\
\hline Telenovela & 21,25 & 0 & 89,5 & 11,75 & 122,5 \\
\hline Totales & 375,5 & 339,75 & 260,25 & 139,5 & 1115 \\
\hline
\end{tabular}

Elaboración propia

\section{REALITY SHOW Y MAGACÍN}

Gráfico 2. Formatos de televisión emitidos

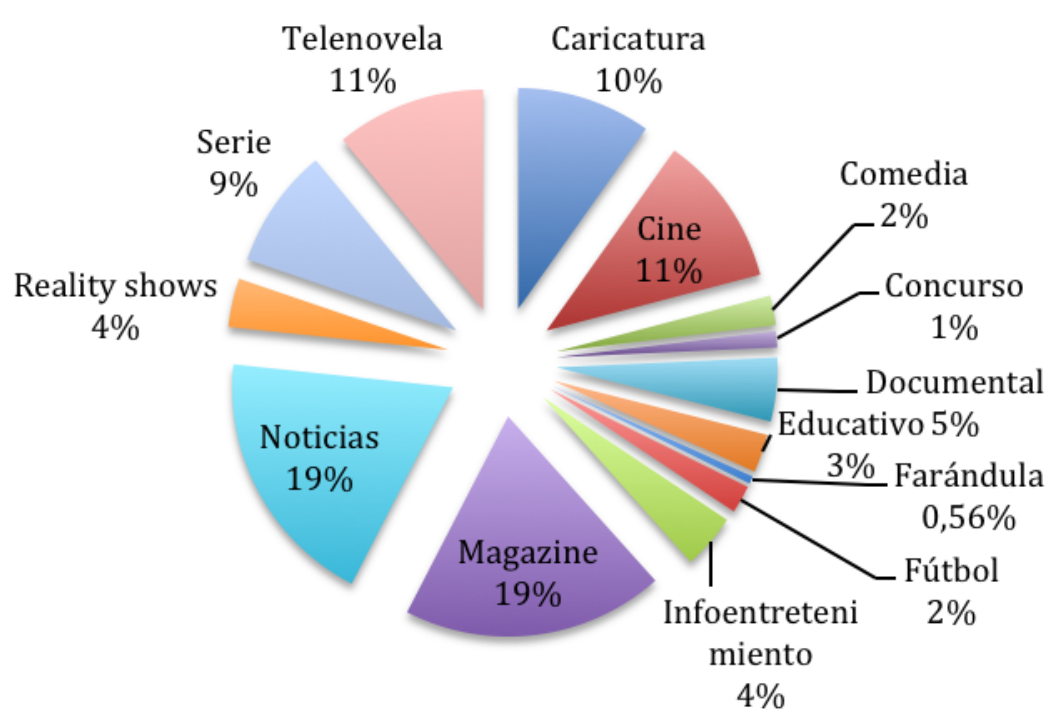

Elaboración propia

La tabla 4 presenta la clasificación por formatos de los contenidos de la televisión emitida en los países andinos. Los grandes agregados están representados en el gráfico 2. 
Los formatos que ocupan mayor tiempo de emisión son, en orden de magnitud: magazine, noticias, cine, telenovelas y caricatura que juntos suman el $70 \%$ de la parrilla.

La ficción es el género que ocupa la mayor porción de contenidos en pantalla; está conformada por los formatos de cine (11\%), caricatura (10 \%), telenovela (11 \%) y series (9 \%) que aportan de forma casi proporcional.

Los formatos con aportes menores al 5 \% son: comedia, concurso, documental, educativo, infoentretenimiento, reality shows, fútbol y farándula. Llaman la atención los tres últimos en razón de ser espacios identificados con el entretenimiento y de gran consumo lo que hace suponer que el entretenimiento está migrando de los formatos tradicionales.

Los formatos de noticias y documentales, tradicionalmente identificados y empleados en el género informativo, representan el $24 \%$ del tiempo de emisión. Estos formatos son utilizados en otros géneros; así se explica que en la sumatoria según la clasificación de géneros de la presente investigación (gráfico 1) la proporción del género informativo sea del $17 \%$, lo que confirmaría la hibridación de formatos y géneros en la televisión contemporánea.

Existen formatos que no son emitidos en ciertos medios, como:

- Caricaturas de origen nacional en los medios privados,

- Comedia de origen nacional en medios púbicos,

- Concursos de origen nacional y extranjero en medios púbicos,

- Telenovelas de origen nacional en medios públicos,

- Farándula de origen extranjero en medios privados y públicos,

- Fútbol de origen extranjero en medios públicos.

La situación identificada confirma la vocación de los medios en el sentido de aporte a la identidad, valores nacionales de los medios públicos y la estrategia de beneficios de los medios privados. Las caricaturas de origen nacional son fruto de procesos de formación de creadores y orientación del gusto de audiencia por temáticas nuevas y cercanas a la historia nacional; eso explica la emisión de este formato en medios públicos. Las comedias son emitidas principalmente en medios privados, algunas son de factura internacional; los propios medios se encargan de producirlas, algunos de estas producciones son criticadas en tanto emplean recursos fáciles centrados en la mofa y la denigración de las personas.

Los concursos de origen nacional y extranjero no están presentes en medios púbicos posiblemente por los patrocinios comerciales que demandan para su puesta en escena; sin embargo, y en razón de la observación específica realizada en la investigación, no se puede asegurar que el formato esté ausente a futuro en los medios públicos en tanto haya dependencias de temas educativos o relacionados con los intereses ciudadanos.

Las telenovelas de origen nacional no son emitidas en medios públicos. Aunque la telenovela ha sido identificada como el formato «reina» en Latinoamérica no alimenta los medios públicos cuyo fin es aportar en forma proporcional en todos los géneros 
audiovisuales y ya los medios privados mantienen una alta proporción de ficción; similar argumento pude aplicarse para explicar la no presencia de fútbol de origen extranjero en medios públicos.

La farándula de origen extranjero no está presente en medios privados y públicos, los programas de farándula constituyen 0,56 \% de los contenidos emitidos en la televisión andina observada, son los de menor aporte, lo que explica que no existan programas de origen foráneo.

Gráfico 3. Contenidos de origen extranjero emitidos según formatos

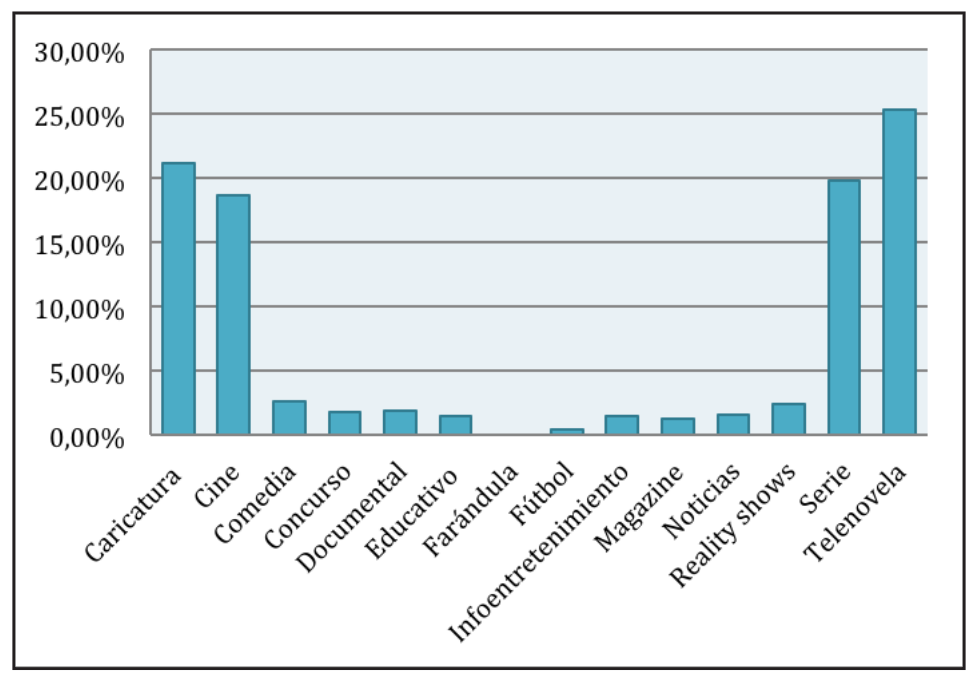

Elaboración propia

Gráfico 4. Contenidos de origen nacional emitidos según formatos

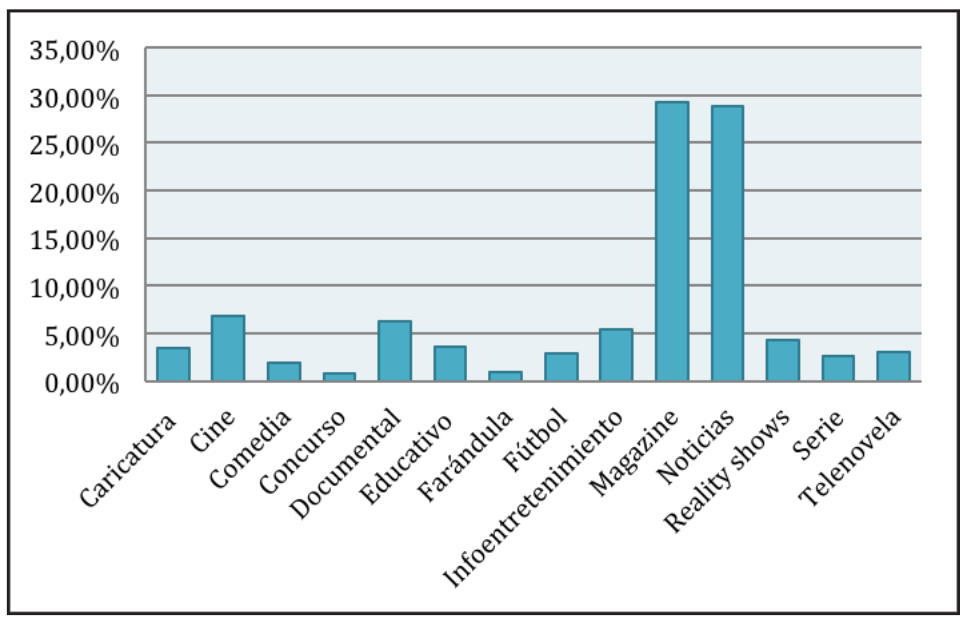

Elaboración propia 
Los gráficos 3 y 4 muestran el contraste entre contenidos de origen extranjero y de origen nacional, emitidos en las estaciones de televisión del área andina, los formatos extranjeros en mayor proporción son caricaturas, cine, series y telenovelas, es decir, la televisión andina importa ficción. Los formatos de origen nacional son, en mayores proporciones, magazines, noticias, cine, documentales e infoentretenimiento; la producción nacional está vinculada a la actualidad pero hay significativas cuotas de aporte en ficción.

Gráfico 5. Contenidos emitidos en estaciones privadas de televisión según formatos

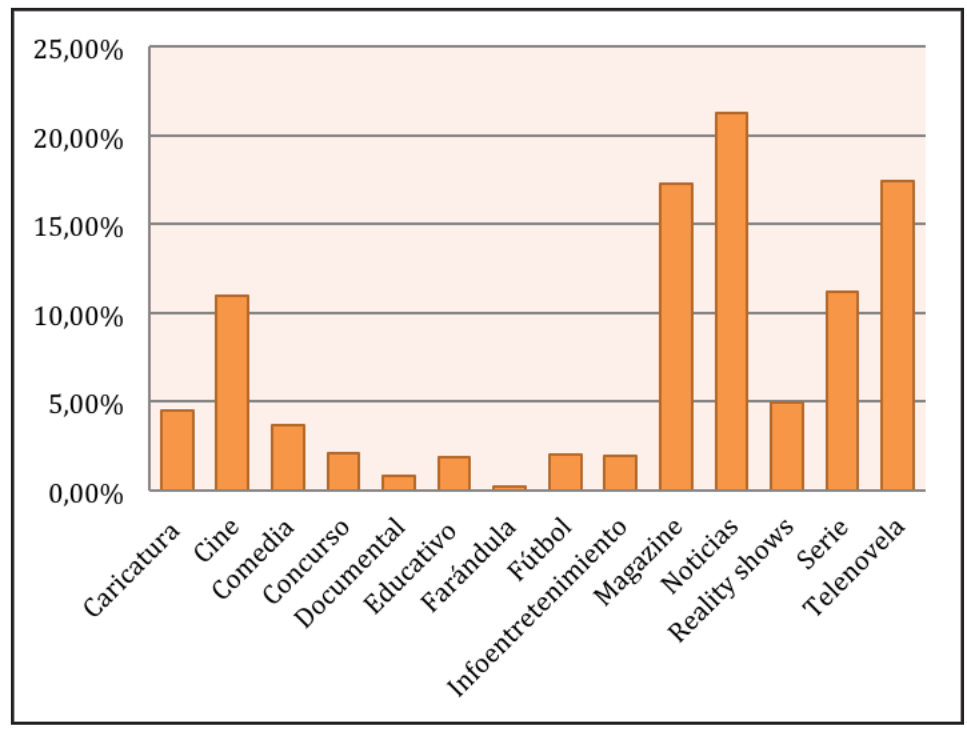

Elaboración propia

Gráfico 6. Contenidos emitidos en estaciones públicas de televisión según formatos

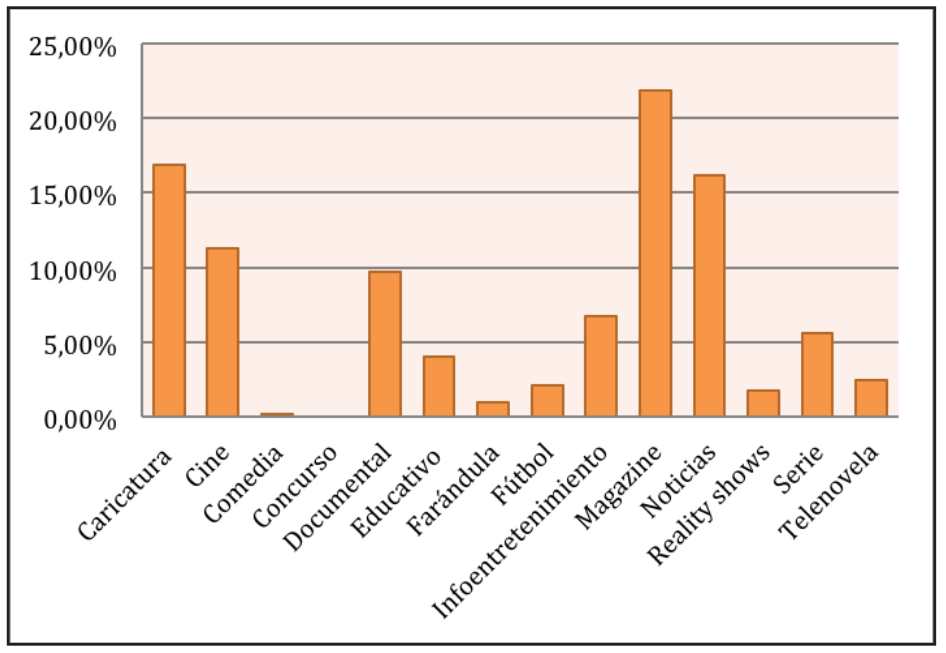

Elaboración propia 
Los gráficos 5 y 6 presentan las relaciones porcentuales de contenidos emitidos en estaciones privadas y públicas de televisión en el área andina. Los formatos con aportes mayores en estaciones privadas (más de $10 \%$ ) son cine, magacines, noticias, series y telenovelas, mientras que en las estaciones públicas (aportes mayores al $10 \%$ ) son caricaturas, cine, magacín y noticias. Los formatos de cine, magacín y noticias que corresponden a los géneros de ficción, entretenimiento e información son los de mayor emisión en la televisión pública y privada del área andina.

Fruto de las entrevistas realizadas para determinar los factores que influyen en la creación de formatos y contenidos de televisión local lograron ubicarse cuatro factores: condicionantes culturales, y condicionantes económicos, formación de recursos humanos y narrativas audiovisuales.

Los condicionantes culturales son una limitante en razón de la diversidad cultural entre las regiones; por ejemplo, el habitante, de costa tiene ciertas preferencias y el consumo que hace de contenidos marca los horarios de programación; además, las costumbres de la comunidad configuran un perfil de televidente conservador poco dispuesto a recibir formatos dinámicos que corre el riesgo de quedar rezagado frente a la evolución de tecnologías y creatividad en la presentación de contenidos.

Otro limitante es el factor económico, que en ocasiones es catalogado como el principal. La ausencia de apoyo del sector privado lleva a que los productores no encuentren rentables ciertos formatos y decanten por programas mucho más fáciles: videoclips, chismes, concursos; la razón estaría en parte en los factores culturales que no permiten valorar la importancia cultural del trabajo audiovisual; así, usuarios y empresas no invierten en contenidos, prefieren lo más económico que usualmente lo encuentran fuera, dejan en segundo plano la producción nacional. En este mismo apartado y consecuencia de lo señalado es la escasa comercialización de herramientas y equipamiento audiovisual: los realizadores deben importar sus equipos y enfrentar costos arancelarios.

Los recursos humanos calificados son también una condicionante; esta carencia ha marcado tanto a realizadores como a productores. Ahora gracias a la formación en universidades y al acceso a la información a través de Internet se ha superado en parte la falta de recursos humanos cualificados; los canales y las productoras empiezan a entender mejor la producción, y las industrias están dispuestas a poner el dinero para "ganar y ganar". A la par del acceso a la información y al conocimiento los contextos legales y nuevas formas de circulación de contenidos bajo licencias de creaciones comunes permiten consolidar sectores como la animación y el formato de caricaturas.

Otra carencia son los recursos argumentales; faltan narraciones a través de las cuales se puedan contar historias que realmente lleguen a las personas, se trata de saber contar historias para que la gente logre engancharse con un producto; la audiencia está absorbida por una gran oferta, es complejo lograr que un nuevo contenido llegue, y hay tanta saturación de información que la gente empieza a ver historias similares. 
Los formatos que realizadores y operadores audiovisuales estiman pertinentes y factibles de elaborar en estaciones locales de televisión de los países andinos serán el resultado de identificar las características de las audiencias ¿Quiénes son? ¿Dónde están? ¿Cuántos son? Así podrán planificarse de mejor los formatos y programas.

Debe considerarse que para crear contenidos son necesarios recursos que para los canales locales son una gran limitante y llevan a sus propietarios a programar con criterios mercantiles quedándose casi solo con noticieros y programas musicales como producción propia; el resto es relleno con programas internacionales. Frente a ello se proponen alternativas como la participación de universidades, ministerios y gobiernos locales para ayudar a financiar; sería una relación estratégica entre productores e instituciones porque para un solo canal local es imposible; así podrían elaborar grandes contenidos.

Los programas sugeridos por los entrevistados son de aventura, deportes extremos, turismo con visión internacional sobre la base de los atractivos naturales de la región, perfiles documentales sobre personas que han aportado a la cultura o a la ciencia. Antes de proponer un formato, las experiencias de Discovery e History Channel son referentes en tanto debieron evolucionar hacia el reality, aunque detrás hay un trabajo de producción y guion; la gente aprende a través de algo muy atractivo, aprenden historia a través de un objeto. El reality puede utilizarse en programas educativos o científicos, puede generar dinero pero tienen el toque cultural. Una de las tendencias entre los entrevistados es el reality por audiencia y costos. El formato es atractivo e interesante, y se presta para enseñar, aunque no hay consenso en la tarea educativa de la televisión.

Otra tendencia es la combinación entre documental, reality y más formatos en tanto acerquen a las comunidades, permitan conocer, saber cómo viven, qué hacen en pueblos vecinos para fomentar la identidad y la cultura. Uno de los argumentos de la televisión local es fortalecer la identidad; por ello el formato pertinente será aquel que ayude a construir comunidad, a identificarse entre ciudadanos.

A diferencia de lo que sucede en las capitales, los canales de televisión locales comprometen casi todas sus capacidades en ensayar iniciativas que atiendan a sus audiencias; por lo tanto, todas esas iniciativas son válidas.

\section{Conclusiones}

Los cambios de fondo de la TDT estarían en la calidad de los contenidos emitidos en géneros y formatos de televisión. La presente investigación buscó determinar los formatos vigentes en el área andina para a través de ellos llegar a la calidad de la oferta televisiva. También procuró identificar el formato adecuado para que las estaciones locales generen contenidos en la transición hacia la TDT.

La calidad como pluralismo, innovación en géneros y formatos aún es tarea pendiente, aunque hay evidencia respecto a crear formatos propios y contenidos de origen nacional. Es alentador saber que 64 \% de los contenidos emitidos en la televisión del área andina es de origen nacional frente a $36 \%$ extranjero; como se mencionó antes los operadores 
públicos y privados pueden crear una televisión con identidad regional de mantener e incrementar la cuota de producción nacional.

Las proporciones de géneros en la televisión andina deben equilibrarse, faltan formatos y programas para espacios de formación, educación, cultura, opinión, política inclusive para deportes más allá del fútbol. Los formatos más utilizados son magacín, noticias, cine, telenovela y caricatura, que son el 70 \% de la emisión. Es valioso señalar que las caricaturas de origen nacional tiene un espacio destacado en la televisión del área andina, tal vez porque la televisión infantil es fundamental para construir cohesión y tejido público; canales como Señal Colombia producen caricaturas de alta calidad reconocidas internacionalmente.

La no emisión de ciertos formatos en medios públicos o privados confirma las vocaciones de servicios público y mercantil, respectivamente; asimismo los formatos importados están en mayor proporción en estaciones privadas

Una de las aproximaciones a la definición de calidad señala que es brindar a la comunidad información profunda e independiente que ayude a cumplir el derecho a la comunicación, acercar contenidos que estimulen la cultura, la educación, el conocimiento; por ello optar por el formato que ayude a construir comunidad, a identificarse entre ciudadanos, a acercar a las regiones y comunidades será implícitamente un formato que va en dirección de la televisión de calidad.

El formato sugerido para las estaciones locales está entre el reality y una hibridación entre documental reality u otros formatos siempre que estén cercanos a los ciudadanos, a escuchar sus necesidades y expectativas

Hay cuatro limitantes para la creación de formatos, identificadas por los realizadores, productores e investigadores audiovisuales: condicionantes culturales, recursos económicos escasos, falta de recursos humanos calificados y deficientes narrativas audiovisuales. Estas limitantes están superándose gracias al acceso a la información a través de internet, la oferta académica de universidades y el trabajo coordinado entre realizadores e instituciones públicas y privadas.

La primera hipótesis de la investigación «Los formatos más emitidos en las estaciones de televisión de los países del área andina corresponden al género de entretenimiento y son producciones extranjeras» es aceptada; la información de sustento está en el cuadro 4 y en los gráficos 1 y 2.

La segunda hipótesis «Las limitaciones para generar formatos están relacionas con la creatividad más que con otros factores» no es aceptada porque las limitaciones son condicionantes culturales, recursos económicos escasos, falta de recursos humanos calificados y deficientes narrativas audiovisuales.

La tercera hipótesis "Los formatos sugeridos a las estaciones locales de televisión para la transición hacia la TDT son adaptaciones con alto componente local" es aceptada ya que la hibridación de formatos con contenidos cercanos a los necesidad y a las exceptivas de los ciudadanos es la alternativa sugerida para la televisión local. 


\section{Bibliografía}

AGUADED, I. (2005). Televisión de calidad. Revista Comunicar. Núm. 25, págs. 17-18.

Recuperado el 20 de marzo de 2014. Disponible en: http://www.americatv.com.pe/programacion

ALBORNOZ, L. E GARCÍA-LEIVA, M. (Eds.) (2012). La televisión digital terrestre. Buenos Aires: La Crujía.

AMADO, A. (2013). Televidente-ciudadano busca televisión televisiva. En Rincón, O. (2013) (Editor): Zapping TV. Bogotá: Friedrich-Ebert-Stiftung FES (Fundación Friedrich Ebert).

AMÉRICA TV (2014). Programación. Recuperado el 07 de mayo de 2014. Disponible en http://www. americatv.com.pe/programacion.

ATB (2014). Programación. Recuperado el 04 de mayo de 2014. Disponible en http://www.atb.com. bo/programacion/

BIZBERGE, A., KRAKOWIAK, F., LABATE, C., E, MORONE, R. (2013). Políticas de TDT: del predominio del mercado al desafío por un sistema democrático de televisión. En G. MASTRINI, E A. BIZBERGE, (Editores) (2013). Las políticas de comunicación en el siglo XXI. Buenos Aires: La Crujía

BOLIVIA informa (2012). Publicidad en canales de televisión: ATB mantiene liderazgo en publicidad. Recuperado el 11 de abril de 2014. Disponible en http://reyquibolivia.blogspot.com/2012/07/ publicidad-en-canales-de-television-atb.html

CAMACHO, R., (2005). Televisión de calidad: distinción y audiencia. Revista Comunicar. Núm. 25, págs. 29-32. Recuperado el 13 marzo de 2014. Disponible en file://Users/abel/Downloads/DialnetTelevisionDeCalidad-1367968\%20(1).pdf

CAN. Comunidad Andina de Naciones (2014). ¿Qué es la CAN? Recuperado el 11 de abril de 2014. Disponible en http://www.comunidadandina.org/Quienes.aspx

CARACOL TV-Colombia (2014). Programación. Recuperado el 05 de mayo de 2014. Disponible en http://www.caracoltv.com/programacion?d=1Et=n) (05-05-2014.

DANTA, R. (2009). TV y capitalización del tiempo de ocio. La programación como medio de producción, en RLCS, Revista Latina de Comunicación Social, 64, págs. 572 a 584. Recuperado el 07 de mayo de 2014. Disponible en http://www.revistalatinacs.org/09/art/47 _ 846 _ ULEPICC _ 04/ RLCS _ art846.pdf

ECUADOR TV (2014). Programación. Recuperado el 07 de mayo del 2014. Disponible en http://www. ecuadortv.ec/interna.php?c $=8896$

ECUAVISA (2014). Programación. Recuperado el 07 de mayo del 2014. Disponible en http://www.ecuavisa.com/programacion

Fayerwayer (2014). La Televisión Digital Terrestre en Latinoamérica. Recuperado el 15 de mayo de 2014. Disponible en http://www.fayerwayer.com/2012/05/la-television-digital-terrestre-en-latinoamerica/

FUENZALIDA, V. (2011). Situación de la televisión pública en América Latina. Diálogos de la Comunicación. N. 74 , págs. 1-21. Recuperado el 09 de mayo de 2014. Disponible en http://www.dialogosfelafacs. net/wp-content/uploads/2012/01/74-revista-dialogos-situacion-de-la-television-Publica-pdf

GALÁN-FAJARDO, E. E RUEDA-LAFFOND J. (2011). Narrativizando la historia: un enfoque interdisciplinar aplicado al relato televisivo. Palabra Clave. Volumen 14. Número 1, págs. 85-99. Bogotá: Universidad de la Sabana. 
GUERRERO, E. (2010). El desarrollo de proyectos audiovisuales: adquisición y creación de formatos de entretenimiento. Comunicación y Sociedad. Vol. XXIII. Núm. 1: págs. 237-273. Pamplona: Universidad de Navarra.

HELLÍN, P., ROJO, P. E SAN NICOLÁS, C. (2009). La televisión digital terrestre en Murcia. Sevilla: Comunicación Social.

HERNÁNDEZ, G. (2008). Las tres «T» de la comunicación en Venezuela Televisión, teoría y televidentes. Caracas: Universidad Católica Andrés Bello. Recuperado el 08 de abril de 2014. Disponible en http://goo.gl/n2MFxa

LAMAC. Consejo Latinoamericano de Publicidad en Multicanales (2013). América Latina. Imparable Crecimiento de la TV Paga en Latinoamérica. Recuperado el 10 de abril de 2014. Disponible en http://www.lamac.org/venezuela/comunicados/imparable-crecimiento-de-la-tv-paga-enlatinoamerica/. De B. LEÓN, (Coord.) (2008). Transformar la televisión. Otra televisión es posible. Sevilla: Editorial Comunicación Social.

LÓPEZ, N. E GÓMEZ, L. (2012). Géneros, formatos y programas de televisión preferidos por los jóvenes. Icono 14. Vol.10. N.3 3, páginas: 258-283. ISSN 1697-8293. Madrid: España.

LÓPEZ, N., GONZÁLEZ, P. E MEDINA, E. (2011). Jóvenes y televisión en 2010: un cambio de hábitos. Zer. Vol. 16. Núm. 30, páginas 97-113. Universidad de País Vasco.

MARÍN, V. (2005). La televisión de calidad y la familia. Comunicar. Núm. 25, págs. 225-230. Huelva: Universidad de Huelva. Recuperado el 13 de marzo de 2014. Disponible en file://Users/abel/ Downloads/Dialnet-LaTelevisionDeCalidadYLaFamilia-1368022.pdf. De M. MEDINA (2007). Explotación económica de las series familiares de Televisión. Comunicación y Sociedad. Vol. XX. Núm. 1, págs. 51-85. Pamplona: Universidad de Navarra.

OCENDI, Observatorio del Ocio y Entretenimiento Digital (2012). Preferencia juvenil en nuevos formatos de televisión. Tendencias de consumo en jóvenes de 14 a 25 años», Madrid: España. Recuperado el 05 de mayo del 2014. Disponible en http://www.ocendi.com/descargas/informetv _ web.pdf.

OROZCO, G. E VASSALLO, M. (Coord.) (2013). Memoria social y ficción televisiva en los países Iberoamericanos: OBITEL 2013. Porto Alegre: Editora Meridional.

PAJONI, H., DE LA TORRE, L. E BESADA, M. (2013). Noticieros en Argentina: la representación de la actualidad en las encrucijadas políticas. Revista de Comunicación. Número 12, págs. 158-182. Buenos Aires. Universidad Católica Argentina.

PERIS, Á. (2009). La tele realidad y la televisión pública, una coexistencia difícil. En Francés, Miquel (Coord.) (2009): Hacia un nuevo modelo televisivo. Barcelona: Gedisa

PIÑÓN, J. (2013). Televisión hispana en Estados Unidos: Una industria que crece y se diversifica. En RINCÓN, O. (2013) (Editor). Zapping TV. Bogotá: Friedrich-Ebert-Stiftung FES (Fundación Friedrich Ebert).

RINCÓN, O. (2013) (Editor). Zapping TV. Bogotá: Friedrich-Ebert-Stiftung FES (Fundación Friedrich Ebert).

RIVERA, J. (2014). La TV Invisible I: Tv pública colombiana de calidad. Recuperado el 18 de mayo de 2014. Disponible en http://jeronimorivera.com/2014/05/11/la-tv-invisible-i-tv-publica-colombianade-calidad/. 
ROMÁN, M. (2012). TDT en España y dividendo digital. Revista Estudio sobre el Mensaje Periodístico. Vol. 18, (noviembre 2012): págs. 801-809. Madrid: Universidad Complutense.

ROS, F. (2009). La transición hacia la TDT. En Francés, Miquel (Coord.) (2009): Hacia un nuevo modelo televisivo. Barcelona: Gedisa

SCOLARI, C. (2013). Narrativas transmedia. Barcelona: Deusto

Señal Colombia (2014). Programación. Recuperado el 06 de mayo de 2014. Disponible en http://www. senalcolombia.tv/programacion.

SOTO-HERNÁNDEZ, S. E NAUMIS-PEÑA, C. (2014). "Análisis bibliotecológico de los noticieros televisivos mexicanos en la Web. El profesional de la información, enero-febrero, v. 23, n. 1, págs. 80-86.

TDT-Foro Latinoamérica (2013). En Bolivia no hay medición de audiencias; sin ratings. Recuperado el 11 de abril del 2014. Disponible en http://www.tdt-latinoamerica.tv/foro/en-bolivia-no-haymedicion-de-audiencias-sin-ratings-t12635.html.

De Tu Ves HD (2014). Guía de programación. Recuperado el 12 de mayo de 2014. Disponible en http:// www.tuves.com.bo/guia-de-programacion/.

TV Perú (2014). Programación. Recuperado el 06 de mayo de 2014. Disponible en http://www.tvperu. gob.pe/tv-hd/day.listevents/2014/05/05/37.html) (06-05-2014.

VÁZOUEZ, T. (2009). Evaluación de la calidad de la programación infantil de las televisiones generalistas españolas. Revista Latina de Comunicación Social, Núm. 64, págs. 844-861. La Laguna (Tenerife): Universidad de La Laguna. Recuperado el 13 de marzo de 2014. Disponible en http:// www.revistalatinacs.org/09/art/866 _ CEU/RLCS _ art866.pdf 